\title{
Factors Associated with Patient's Delay in Tuberculosis Treatment in Bahir Dar City Administration, Northwest Ethiopia
}

\author{
Endalew Gebeyehu, ${ }^{1}$ Muluken Azage, ${ }^{2}$ and Gedefaw Abeje ${ }^{2}$ \\ ${ }^{1}$ Department of Pharmacology, College of Medicine and Health Sciences, Bahir Dar University, P.O. Box 79, Bahir Dar, Ethiopia \\ ${ }^{2}$ Department of Public Health, College of Medicine and Health Sciences, Bahir Dar University, P.O. Box 79, Bahir Dar, Ethiopia \\ Correspondence should be addressed to Muluken Azage; mulukenag@yahoo.com
}

Received 6 February 2014; Revised 3 May 2014; Accepted 3 May 2014; Published 20 May 2014

Academic Editor: Valeria Rolla

Copyright ( $) 2014$ Endalew Gebeyehu et al. This is an open access article distributed under the Creative Commons Attribution License, which permits unrestricted use, distribution, and reproduction in any medium, provided the original work is properly cited.

Background. Unknown proportions of tuberculosis cases remain undiagnosed and untreated as result of several factors which further increases the number of tuberculosis cases per index case. Objective. To identify factors associated with patient's delay in initiating treatment of tuberculosis. Methods. Cross-sectional study was employed from January to April, 2013, in Bahir Dar Ethiopia. A total of 360 patients were included. Data were collected from tuberculosis patients using a semistructured questionnaire. Data were entered and analyzed using SPSS version 16 windows. Multivariate logistic regression analysis was used to identify factors associated with patient delay. Results. Of all patients, 211 (62\%) sought medical care after the WHO recommended period (21 days). The median patient delays of smear positive, smear negative, and extrapulmonary patients were 27 (IQR: 10-59), 30 (IQR: 9-65), and 31 (IQR: $10-150$ ) days, respectively, with statistically significant variations among them (ANOVA: $F=5.96 ; P<0.003$ ). Place of residence and educational status were the predictors of patient delay. Conclusion. Around two-thirds of all patients and more than half of smear positive tuberculosis patients were delayed in seeking medical care within the recommended period. Provision of DOTS service in the vicinity and health education on TB may reduce patient delay and its consequences.

\section{Introduction}

Tuberculosis (TB) is a major public health burden throughout the world. Almost one-third of the world population (about 2 billion) is infected with Mycobacterium tuberculosis and during the past decade even industrialized countries have faced a resurgence of tuberculosis. Currently, TB is the leading cause of mortality among infectious diseases worldwide. About $95 \%$ of TB cases and $98 \%$ of deaths due to TB occur in developing countries [1].

Ethiopia is one of the 22 countries with high TB burden [1]. Literatures showed that many TB cases remain undiagnosed and untreated in many countries with high incidence of $\mathrm{TB}$ that increases the risk of $\mathrm{TB}$ transmission in the community [1-8]. Studies on different parts of the world showed that different factors are associated with patient delay. Studies done in African countries mentioned that residence was an important predictor of patient delay in initiating treatment [9-13]. Similarly in Asia and African countries being female was mentioned as a factor for predicting patient delay $[9,10,13-15]$.

According to the WHO Global TB report, 2012, Ethiopia ranks 13 th in the list of 22 high burden countries (HBCs) and 4th in Africa, with an estimated prevalence of all forms of TB in 200 per 100,000 population [16]. Although treatment is available freely, patients are not able to initiate treatment as early as possible. In 2011, of all causes of death in the Amhara region TB was ranked 7 th for adult death. Health facility reports showed that patients failed to seek medical care within the recommended period [17].

There is paucity of credible evidence on the extent of delay in treatment seeking behavior of patients in Amhara region. Credible evidence on predictors of patient delay could be important information to look for new strategy to curb 
the death and spread of TB. Therefore this study aims to investigate the extent of patient delay and its influencing factors among tuberculosis patients in Bahir Dar town. Moreover, the data from this study will identify barriers for delay in care seeking to strengthen the strategies for prevention and treatment of TB patients.

\section{Methods and Materials}

2.1. Study Design and Period. Institution based cross-sectional study was conducted on tuberculosis patients at DOTS in public health facilities from January to April, 2013.

2.2. Study Setting. The study was conducted in Bahir Dar town which is the capital city of Amhara National Regional State. It is located at $565 \mathrm{~km}$ northwest of Addis Ababa, Ethiopia. The town has a population of 221,991 of whom $49 \%$ were male and the rest were female [18]. There were nine public healthcare facilities (one hospital and eight health centers) in Bahir Dar city administration at the time of the study. All public health institutions were providing smear microscopy and DOTS service to the community [19]. Bahir Dar town was selected because of its more numbers of clinics that conduct TB diagnosis through smear microscopic examination and DOTS service in the region to get the required sample size.

2.3. Sample Size and Sampling Procedures. The sample size was determined using the formula for estimation of population proportion $\left(n=\left[\left(Z_{\alpha / 2}\right)^{2} * p *(1-p)\right] / d^{2}\right)$ where: $Z_{\alpha / 2}$ at $95 \%$ CI (1.96), $d$ marginal error 0.05 , and $p$ proportion obtained from previous study in East Wollega, Ethiopia, in $2006(0.63)$ [20]. With 5\% none response rate, the total sample size of the study was 376. All adult tuberculosis patients registering for DOTS service in the clinics were the study population. Adults who were unable to respond and children were excluded from the study because they may not give appropriate responses to the questionnaire. All patients registering for DOTS were interviewed. To avoid double counting of patients when they change their DOTS clinic, reminder note was attached with the referral sheet to the receiving health facility.

2.4. Data Collection Tools and Quality Assurance. Data were collected using a semistructured questionnaire which has a question of sociodemographic and economic variables, accessibility, and availability of TB service and delay question.The questionnaire was prepared in English first and translated to the local language, Amharic and again back translation to English was made to ensure the consistency of the questions. In addition, pre test was done in an area different from the study area to validity the questionnaire. In this study, patient delay was measured by considering the time from initial onset of sign and symptoms of the disease to first consultation of healthcare facility by the patient. According to WHO recommendation the study subjects were grouped into those who delayed $\leq 21$ days and those delayed $>21$ days and this binary classification was used to identify factors
TABLE 1: Characteristics of tuberculosis patients in DOTS clinic of public healthcare facilities in Bahir Dar city administration, Northwest Ethiopia.

\begin{tabular}{|c|c|c|}
\hline Variables & $\begin{array}{c}\text { Frequency } \\
(n=360)\end{array}$ & Percent \\
\hline \multicolumn{3}{|l|}{ Sex } \\
\hline Male & 214 & 59.4 \\
\hline Female & 146 & 40.6 \\
\hline \multicolumn{3}{|l|}{ Age } \\
\hline$<20$ & 39 & 10.8 \\
\hline $20-39$ & 243 & 67.5 \\
\hline$\geq 40$ & 78 & 21.7 \\
\hline \multicolumn{3}{|l|}{ Place of residence } \\
\hline Urban & 238 & 66.1 \\
\hline Rural & 122 & 33.9 \\
\hline \multicolumn{3}{|l|}{ Marital status } \\
\hline Single & 152 & 42.2 \\
\hline Married & 168 & 46.7 \\
\hline Widowed & 14 & 3.9 \\
\hline Divorced & 26 & 7.2 \\
\hline \multicolumn{3}{|l|}{ Education status } \\
\hline Illiterate & 124 & 34.2 \\
\hline Read and write & 38 & 10.6 \\
\hline Elementary & 56 & 15.6 \\
\hline Junior/secondary & 80 & 22.2 \\
\hline College and above & 62 & 17.5 \\
\hline \multicolumn{3}{|l|}{ Occupation } \\
\hline Employee & 42 & 11.7 \\
\hline Merchant & 24 & 6.7 \\
\hline Farmer & 73 & 20.3 \\
\hline Daily laborer & 57 & 15.8 \\
\hline Student & 65 & 18.1 \\
\hline Housewife & 99 & 27.5 \\
\hline \multicolumn{3}{|l|}{ Smoking habit } \\
\hline Yes & 17 & 4.7 \\
\hline No & 343 & 95.3 \\
\hline \multicolumn{3}{|l|}{ Type of tuberculosis } \\
\hline Pulmonary & 153 & 42.5 \\
\hline Extrapulmonary & 207 & 57.5 \\
\hline \multicolumn{3}{|l|}{$\begin{array}{l}\text { Distance to the nearest } \\
\text { healthcare facility }\end{array}$} \\
\hline$<10 \mathrm{~km}$ & 270 & 75 \\
\hline$\geq 10 \mathrm{~km}$ & 90 & 25 \\
\hline
\end{tabular}

related to patient delay during logistic regression analysis [21]. The completeness of responses to the questionnaires was checked routinely during data collection. Questionnaires with incomplete response were excluded during data entry.

2.5. Data Analysis. Questions were coded and then data were entered and analyzed using SPSS version 16. Frequency runs, 
TABLe 2: Patient delay by TB categories in Bahir Dar city administration, Northwest Ethiopia, 2013.

\begin{tabular}{|c|c|c|c|c|}
\hline & $\begin{array}{c}\text { Smear positive } \\
N(\%)\end{array}$ & $\begin{array}{c}\text { Smear negative } \\
N(\%)\end{array}$ & $\begin{array}{c}\text { Extrapulmonary TB } \\
N(\%)\end{array}$ & $\begin{array}{c}\text { Total } \\
N(\%)\end{array}$ \\
\hline \multicolumn{5}{|c|}{ Patient delay in days ( $\leq 21$ days) } \\
\hline 1-7 days & $16(21.3)$ & $19(24.4)$ & $46(22.2)$ & $81(22.5)$ \\
\hline 8-14 days & $10(13.3)$ & $11(4.1)$ & $18(8.7)$ & $39(10.5)$ \\
\hline 15-21 days & $10(13.3)$ & $3(3.8)$ & $16(7.7)$ & $29(8.1)$ \\
\hline Total & $36(48.0)$ & $33(42.3)$ & $80(38.6)$ & $149(38.3)$ \\
\hline \multicolumn{5}{|c|}{ Patient delay in days ( $>21$ days) } \\
\hline 22-30 days & $8(10.7)$ & $9(11.5)$ & $23(11.1)$ & $40(11.3)$ \\
\hline $31-60$ days & $14(18.7)$ & $15(19.2)$ & $20(9.7)$ & $49(13.6)$ \\
\hline $61-90$ & $5(6.7)$ & $7(9.0)$ & $19(9.2)$ & $31(8.6)$ \\
\hline$>90$ days & $12(16.0)$ & $14(17.9)$ & $65(31.4)$ & $91(25.3)$ \\
\hline Total & $39(52.0)$ & $45(57.7)$ & $127(61.4)$ & $211(61.7)$ \\
\hline
\end{tabular}

cross-tabulations, and sort were checked for data quality management. Descriptive statistics were used to summarize data and tables and figures were used to display results. Adjusted odds ratio with the combination of confidence interval and $P$ value was calculated to identify factors associated with delay in seeking treatment using bivariate and multivariate logistic regression analysis.

2.6. Ethical Clearance. Ethical approval was obtained from Bahir Dar University Ethical Clearance Committee. Permission was taken from Bahir Dar City Health Office and the respective health facilities. Informed verbal consent was obtained from study participants. The study participants were assured that the data were used only for the study purpose and could not be passed to a third party. Moreover, privacy and confidentiality were maintained by giving codes for the questionnaire.

\section{Results}

Of the total 376 study participants, 360 (96\%) were included in the study, whereas the remaining were excluded due to data incompleteness during data analysis. Of the study participants, 59.4\% were males, $33.9 \%$ lived in rural areas, and $34.2 \%$ were illiterate. Fifty-eight percent of the study participants had extrapulmonary TB. Two-thirds of the study participants lived within $10 \mathrm{Km}$ radius to public health facility (Table 1).

3.1. Patient Delay. The median patient's delay of smear positive, smear negative, and extrapulmonary patients was 27 (IQR: 10-59), 30 (IQR: 9-65), and 31 (IQR: 10-150), respectively. The overall median patient delay was 30 days (IQR: 10-96, and the 10th and 90th percentiles were 2 and 385 days, resp.). The maximum patient delays in smear positive, smear negative, and extrapulmonary TB patients were 365 , 380 , and 3650 days, respectively. Ninety-one patients (25.3\%) and $24(6.7 \%)$ came after 90 days and one year, respectively. The mean $( \pm S D)$ patient delay in smear positive, smear negative, and extrapulmonary TB patients was 56 (102), 64

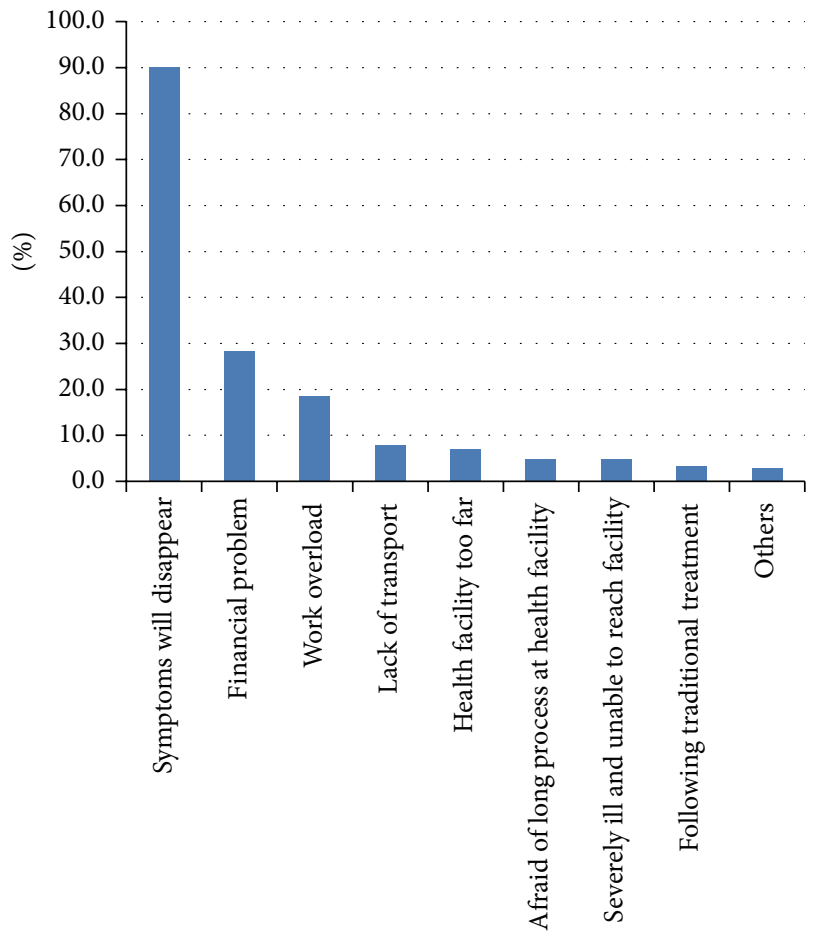

FIgURE 1: Reasons for patient delay among TB patients in public health facilities of Bahir Dar city administration, Northwest Ethiopia (there were multiple responses).

(98), and 192 (467) days, respectively. In ANOVA analysis patient delay had shown a statistically significant variation by categories of TB $(F=5.96 ; P<0.003)$. A total of $211(61.7 \%)$ patients sought medical service after 21 days which is out of the range recommended by WHO. Of all delays, $52 \%$ of smear positive and $57.7 \%$ of smear negative patients and $61.4 \%$ of extrapulmonary TB patients sought medical advice after 21 days (Table 2).

The most frequent reasons mentioned by those who sought treatment after 21 days were thinking that symptoms 
TABLE 3: Logistic regression analysis of factors associated with patient delay in public health care facilities of Bahir Dar town, Northwest Ethiopia.

\begin{tabular}{|c|c|c|c|c|}
\hline \multirow{2}{*}{ Variables } & \multicolumn{2}{|c|}{ Patient delay } & \multirow{2}{*}{ COR (95\% CI) } & \multirow{2}{*}{$\operatorname{AOR}(95 \% \mathrm{CI})$} \\
\hline & $\leq 21$ days & $>21$ days & & \\
\hline \multicolumn{5}{|l|}{ Sex } \\
\hline Male & 87 & 127 & $1.08(0.70,1.65)$ & \\
\hline Female & 62 & 84 & 1.00 & \\
\hline \multicolumn{5}{|l|}{ Age } \\
\hline$<20$ & 19 & 20 & $0.56(0.26,1.22)$ & \\
\hline $20-39$ & 103 & 140 & $0.72(0.42,1.22)$ & \\
\hline$\geq 40$ & 27 & 51 & 1.00 & \\
\hline \multicolumn{5}{|l|}{ Place of residence } \\
\hline Urban & 114 & 124 & 1.00 & 1.00 \\
\hline Rural & 35 & 87 & $2.29(1.43,3.65)^{* *}$ & $1.74(1.04,2.90)$ \\
\hline \multicolumn{5}{|l|}{ Marital status } \\
\hline Single & 65 & 87 & 1.00 & \\
\hline Married & 65 & 103 & $1.18(0.76,1.85)$ & \\
\hline Widowed & 6 & 8 & $1.00(0.33,3.01)$ & \\
\hline Divorced & 13 & 13 & $0.75(0.33,3.79)$ & \\
\hline \multicolumn{5}{|l|}{ Education level } \\
\hline Illiterate & 38 & 86 & $4.75(2.47,9.15)^{* * *}$ & $3.73(1.87,7.44)^{* * *}$ \\
\hline Read and write & 15 & 23 & $3.22(1.39,7.46)^{* *}$ & $2.58(1.08,6.15)^{*}$ \\
\hline Elementary & 20 & 36 & $3.78(1.76,8.11)^{* *}$ & $3.39(1.57,7.33)^{* *}$ \\
\hline Junior/secondary & 34 & 46 & $2.84(1.42,5.68)^{* *}$ & $2.74(1.36,5.49)^{* *}$ \\
\hline College and above & 42 & 20 & 1.00 & 1.00 \\
\hline \multicolumn{5}{|l|}{ Occupation } \\
\hline Employee & 26 & 16 & 1.00 & \\
\hline Merchant & 12 & 13 & $1.92(0.70,5.31)$ & \\
\hline Farmer & 20 & 53 & $4.31(1.92,9.66)$ & \\
\hline Daily laborer & 25 & 32 & $2.08(0.92,4.69)$ & \\
\hline Student & 23 & 42 & $2.97(1.33,6.63)$ & \\
\hline Housewife & 44 & 55 & $2.03(0.97,4.25)$ & \\
\hline \multicolumn{5}{|l|}{ Smoking habit } \\
\hline Yes & 8 & 9 & $0.79(0.85,1.99)$ & \\
\hline No & 141 & 202 & 1.00 & \\
\hline \multicolumn{5}{|c|}{ Distance to the nearest health institutions } \\
\hline$<10 \mathrm{~km}$ & 114 & 156 & 1.00 & \\
\hline$\geq 10 \mathrm{~km}$ & 35 & 55 & $1.15(0.71,1.87)$ & \\
\hline
\end{tabular}

${ }^{*} P$-value $<0.05,{ }^{* *} P$-value $<0.01,{ }^{* * *} P$-value $<0.001$.

will disappear (90\%), financial problem (28.4\%), work overload $(18.5 \%)$, transport problem $(8.0 \%)$, health facility being too far $(7.1 \%)$, being afraid of a long process at health facility $(4.7 \%)$, being severely ill and unable to reach $(4.7 \%)$, on traditional treatment (3.3\%), and others (2.8\%) (Figure 1).

3.2. Factors Associated with Patient Delay. Analysis result of bivariate regression indicated that place of residence, education status, and occupation (farmer and student) were statistically significant association with patient delay (Table 3). But only education status remained statistically significant $(P<$ 0.05 ) after controlling confounding effect with multivariate regression by entering those variables that have a $P$ value of $\leq 0.2$. Illiterate patients were 3.73 times \{AOR: $3.73,95 \%$
CI $(1.87,7.44)\}$ more delayed when compared to patients with college and above educational status. Similarly, patients with eight to twelve grade educational status were 2.74 times \{AOR: 2.74, 95\% CI $(1.36,5.49)\}$ more delayed when compared to patients with college and above educational status (Table 3).

\section{Discussion}

Early detection of cases and treating TB patients are one of the strategies of WHO to reduce the diseases morbidity and mortality throughout the world. The overall median patient delay in this study was 30 days. This finding is lower than studies done in Ethiopia (60-63 days) [4, 22, 23] and other 
countries, Nepal (50 days) [24] and Tanzania (120 days) [12]. However, it is almost consistent with another study done in Ethiopia (28 days) [20]. The median patient's delays of smear positive, smear negative, and extrapulmonary patients were 27, 30, and 31 days, respectively, which is lower than the median patient delays for smear positive (90 days), smear negative (60 days), and extrapulmonary tuberculosis patients (90 days) done in Tigray region, Ethiopia, in 2001 [23]. The discrepancies may be due to accessibility of healthcare facilities since more than two-thirds of participants in this study are living in urban setting. Moreover, it may be the contribution of implementation of health extension programme which promotes healthcare activities in Ethiopia.

In this study, $58 \%$ of the study participants were extrapulmonary TB which is higher than the study done in Ethiopia, Tigray (39\%) [23] and WHO report 2012 (32\%) [16]. This difference may be due to the flow of high proportion of referral and nonreferral patients for availability of extrapulmonary TB diagnosis facility at Bahir Dar where the referral hospital is located.

In this study, educational status of below college level was an independent predictor for patient delay. Illiterate patients and patients with eight to twelve educational status are 3.73 and 2.74 times more likely delay when compared to patients with college and above educational status, respectively. This could be due to the fact that those patients who had education status of college and above level have better information access about TB and more likely to seek medical care from healthcare facilities at early stage of the diseases. Similar findings were reported in previous studies $[25,26]$.

This study has a limitation of recall bias since patient delay was measured by asking about initiation of sign and symptoms retrospectively. Due to the nature of the crosssectional study design underreporting or overreporting of patient delay is unavoidable.

\section{Conclusions}

In this study, more than sixty percent of $\mathrm{TB}$ patients sought treatment after WHO recommended periods (21 days) and educational status was the predictor of patient delay. Therefore, provision of health education on TB should be strengthened to reduce patient delay.
Abbreviations
AIDS: Acquired immunodeficiency syndrome
AOR: Adjusted odds ratio
CI: Confidence interval
COR: Crude odds ratio
DOTS: Direct observed treatment short course
HIV: Human immunodeficiency virus
MDG: Millennium development goal
MTB: Mycobacterium tuberculosis
SPSS: Statistical packages for social science
TB: Tuberculosis.

\section{Conflict of Interests}

The authors declare that there is no conflict of interests regarding the publication of this paper.

\section{Authors' Contribution}

Endalew Gebeyehu conceived, designed, and participated in data collection, supervised the data collection and interpretation of data, and revised the paper. Muluken Azage conceived, designed, and analyzed the data and wrote the paper. Gedefaw Abeje participated in design conception, supervised the data collection, and revised the paper. All authors read and approved the final paper.

\section{Acknowledgments}

The authors acknowledge Bahir Dar University for financing this research work. The authors would like to thank the data collectors for their commitment of during data collection and study participants for their willingness to participate in the study. The authors also thank the staff of the College of Medicine and Health Sciences, Bahir Dar University, for their constructive comments during proposal conception.

\section{References}

[1] Federal Ministry of Health, Ethiopian Population Based National TB Prevalence Survey Research Protocol, Federal Ministry of Health, Addis Ababa, Ethiopia, 2009.

[2] Advisory Council for the Elimination of Tuberculosis, "Essential components of a tuberculosis prevention and control program. Recommendations of the Advisory Council for the Elimination of Tuberculosis," Morbidity and Mortality Weekly Report, vol. 44, no. RR-11, pp. 441-416, 1995.

[3] C. Auer, J. Sarol Jr., M. Tanner, and M. Weiss, "Health seeking and perceived causes of tuberculosis among patients in Manila, Philippines," Tropical Medicine and International Health, vol. 5, no. 9, pp. 648-656, 2000.

[4] M. Demissie, B. Lindtjorn, and Y. Berhane, "Patient and health service delay in the diagnosis of pulmonary tuberculosis in Ethiopia," BMC Public Health, vol. 2, no. 1, article 23, 2002.

[5] P. M. Pronyk, M. B. Makhubele, J. R. Hargreaves, S. M. Tollman, and H. P. Hausler, "Assessing health seeking behaviour among tuberculosis patients in rural South Africa," International Journal of Tuberculosis and Lung Disease, vol. 5, no. 7, pp. 619-627, 2001.

[6] World Health Organization, Toman's Tuberculosis: Case Detection, Treatment, and Monitoring-Questions and Answers, WHO, Geneva, Switzerland, 2nd edition, 2004.

[7] Disease Prevention and Control Department, Manual: Tuberculosis and Leprosy Prevention and Control Team, MOH of Ethiopia, Addis Ababa, Ethiopia, 3rd edition, 2005.

[8] K. Jochem and J. Walley, "Determinants of the tuberculosis burden in populations," in Tuberculosis-An Interdisciplinary Perspective, J. D. H. Porter and J. M. Grange, Eds., pp. 33-48, Imperial College, London, UK, 1999.

[9] S. D. Lawn, B. Afful, and J. W. Acheampong, "Pulmonary tuberculosis: diagnostic delay in Ghanaian adults," International 
Journal of Tuberculosis and Lung Disease, vol. 2, no. 8, pp. 635640, 1998.

[10] C. Lienhardt, J. Rowley, K. Manneh et al., "Factors affecting time delay to treatment in a tuberculosis control programme in a sub-Saharan African country: the experience of The Gambia," International Journal of Tuberculosis and Lung Disease, vol. 5, no. 3, pp. 233-239, 2001.

[11] T. W. Steen and G. N. Mazonde, "Pulmonary tuberculosis in Kweneng District, Botswana: delays in diagnosis in 212 smearpositive patients," International Journal of Tuberculosis and Lung Disease, vol. 2, no. 8, pp. 627-634, 1998.

[12] E. R. Wandwalo and O. Mørkve, "Delay in tuberculosis casefinding and treatment in Mwanza, Tanzania," International Journal of Tuberculosis and Lung Disease, vol. 4, no. 2, pp. 133$138,2000$.

[13] J. A. Aluoch, O. B. Swai, and E. A. Edwards, "Study of casefinding for pulmonary tuberculosis in outpatients complaining of a chronic cough at a district hospital in Kenya," The American Review of Respiratory Disease, vol. 129, no. 6, pp. 915-920, 1984.

[14] R. Rajeswari, V. Chandrasekaran, M. Suhadev, S. Sivasubramaniam, G. Sudha, and G. Renu, "Factors associated with patient and health system delays in the diagnosis of tuberculosis in South India," International Journal of Tuberculosis and Lung Disease, vol. 6, no. 9, pp. 789-795, 2002.

[15] J. Ngamvithayapong, H. Yanai, A. Winkvist, and V. Diwan, "Health seeking behaviour and diagnosis for pulmonary tuberculosis in an HIV-epidemic mountainous area of Thailand," International Journal of Tuberculosis and Lung Disease, vol. 5, no. 11, pp. 1013-1020, 2001.

[16] World Health Organization, "Global tuberculosis control," WHO Report WHO/HTM/TB/2012, 2012.

[17] Amhara Regional Health Bureau, Annual Report of Amhara Regional Health Bureau, Amhara Regional Health Bureau, Bahir Dar, Ethiopia, 2011.

[18] Central Statistics Agency (CSA), Summary and Statistical Report of the 2007 Population and Housing Census: Population Size by Age and Sex, Central Statistics Agency (CSA), Addis Ababa, Ethiopia, 2007.

[19] Bahir Dar City Administration Health Office, Annual Report of Bahir Dar City Administration Health Office, Bahir Dar City Administration Health Office, Bahir Dar, Ethiopia, 2011.

[20] T. Wondimu, K. Michael, W. Kassahun, and S. Getachew, "Delay in initiating tuberculosis treatment and factors associated among pulmonary tuberculosis patients in East Wollega, Western Ethiopia," Ethiopian Journal of Health Development, vol. 21, no. 2, pp. 148-156, 2007.

[21] WHO, Treatment of Tuberculosis: Guidelines for National Programmes, World Health Organization, Geneva, Switzerland, 2nd edition, 1997.

[22] A. Tegegn and M. Yazachew, "Delays in tuberculosis treatment and associated factors in Jimma Zone, Southwest Ethiopia," Ethiopian Health Science Journal, vol. 19, no. 1, pp. 29-37, 2009.

[23] M. Mesfin, T. Tasew, I. Tareke, Y. Kifle, W. Karen, and M. Richard, "Delays and care seeking behavior among tuberculosis patients in Tigray of northern Ethiopia," Ethiopian Journal of Health Development, vol. 19, pp. 7-12, 2005.
[24] M. Choudhari, N. Jha, D. K. Yadav, and D. Chaudhary, "Factors associated with patient delay in diagnosis of pulmonary tuberculosis in a district," Journal of Nepal Health Research Council, vol. 10, no. 22, pp. 234-238, 2012.

[25] C. Zhou, R. G. Tobe, J. Chu, H. Gen, X. Wang, and L. Xu, "Detection delay of pulmonary tuberculosis patients among migrants in China: a cross-sectional study," International Journal of Tuberculosis and Lung Disease, vol. 16, no. 12, pp. 1630$1636,2012$.

[26] A. Hussen, S. Biadgilign, F. Tessema, S. Mohammed, K. Deribe, and A. Deribew, "Treatment delay among pulmonary tuberculosis patients in pastoralist communities in Bale Zone, Southeast Ethiopia," BMC Research Notes, vol. 5, article 320, 2012. 


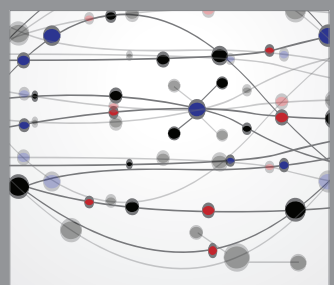

The Scientific World Journal
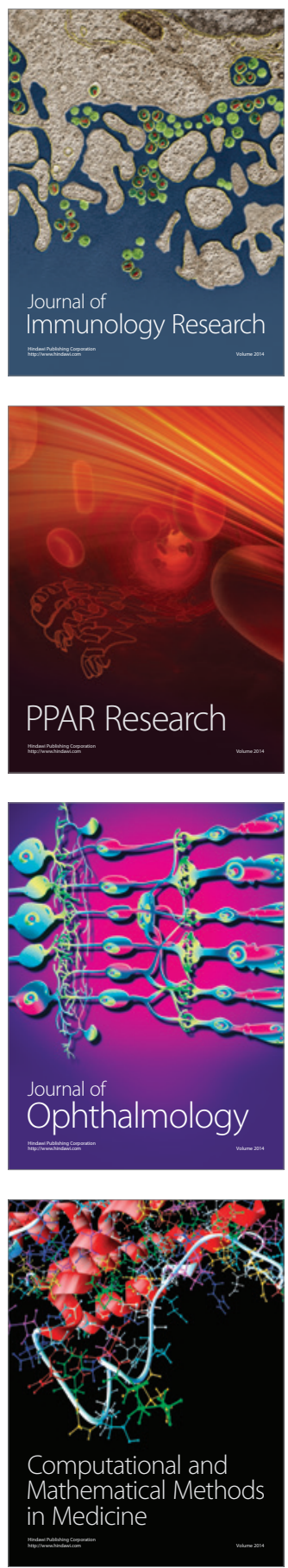

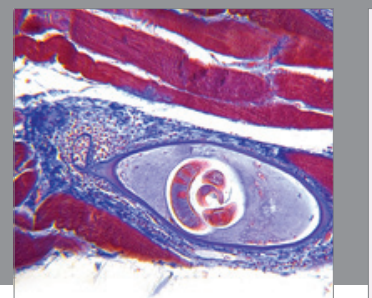

Gastroenterology

Research and Practice
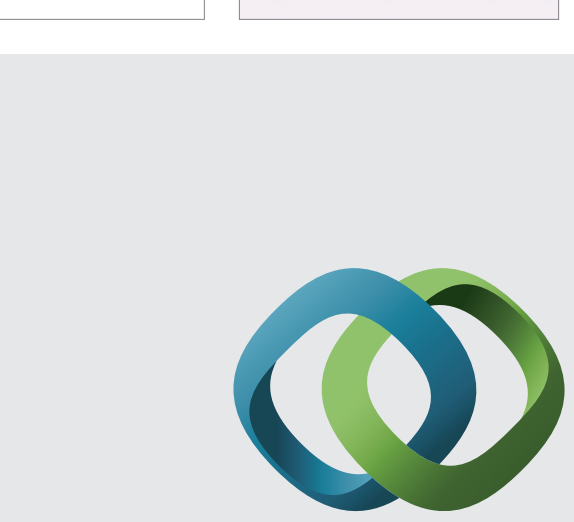

\section{Hindawi}

Submit your manuscripts at

http://www.hindawi.com
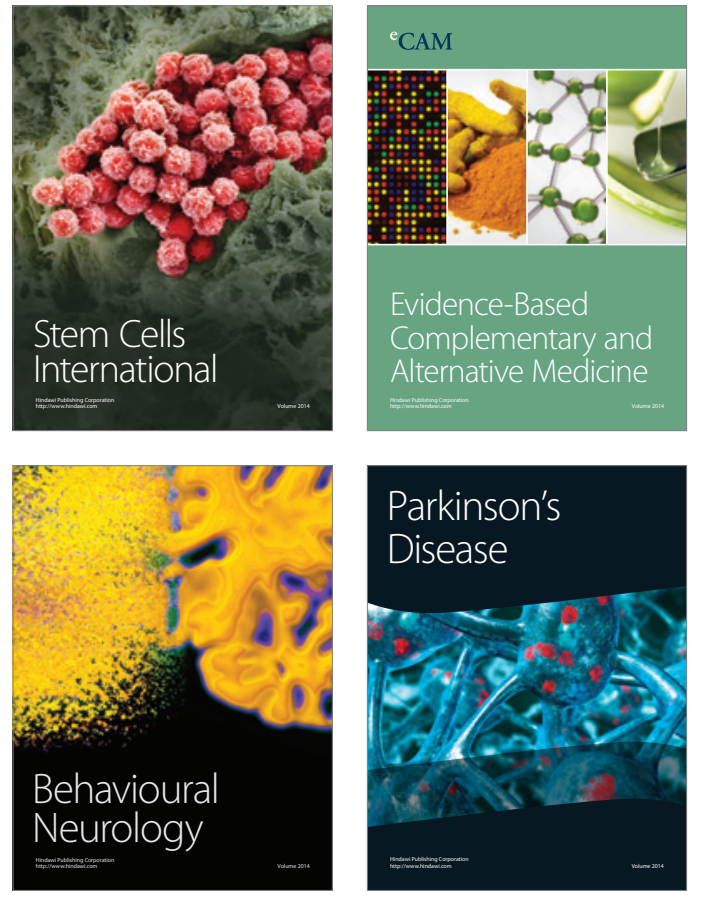
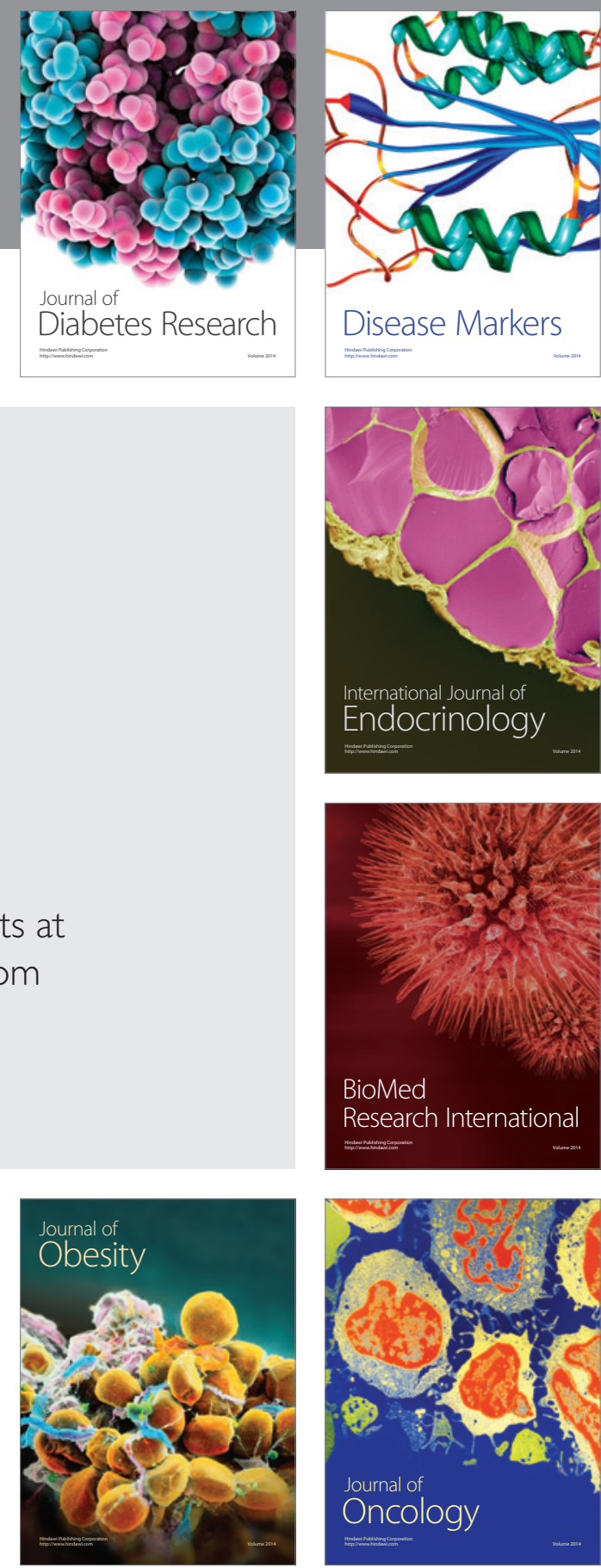

Disease Markers
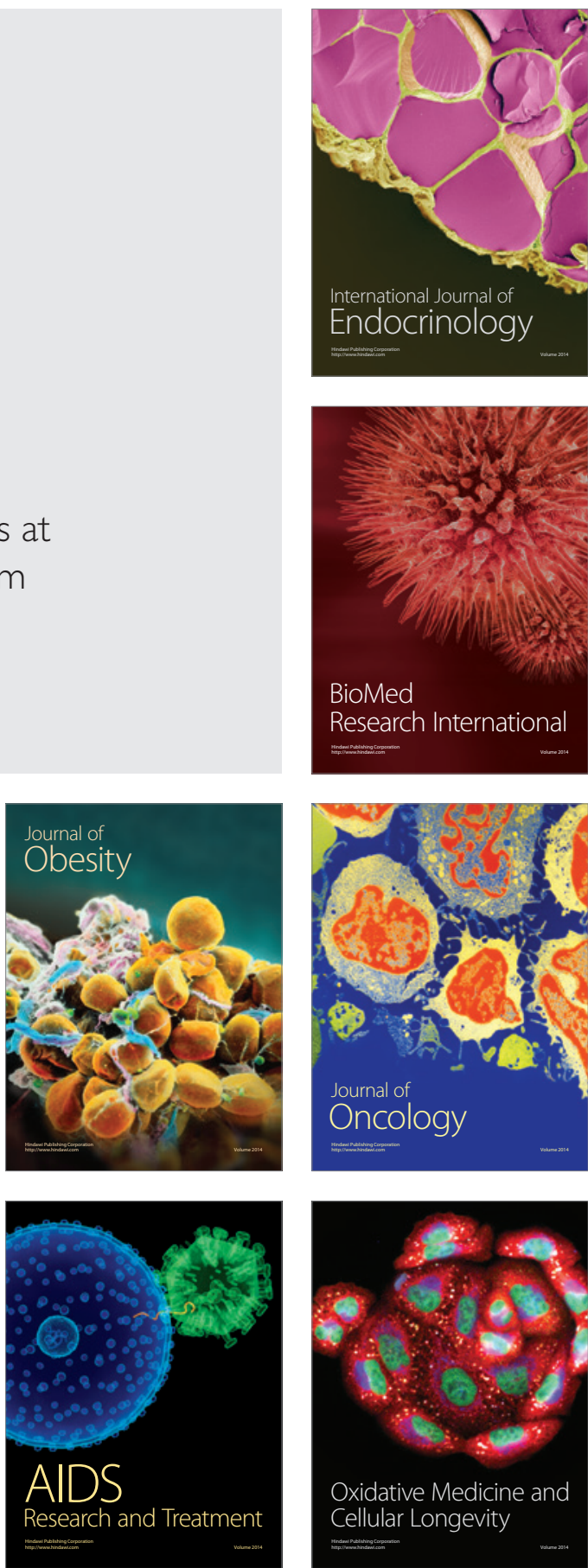